\title{
Diversidade e uso de recursos medicinais do carrasco na APA da Serra da Ibiapaba, Piauí, Nordeste do Brasil
}

\section{CHAVES, E.M.F. ${ }^{1 *}$; BARROS, R.F.M. ${ }^{2}$}

${ }^{1}$ Instituto Federal de Educação, Ciência e Tecnologia do Piauí, Campus Teresina - Sul, Avenida Pedro Freitas, 1020, São Pedro, CEP: 64018-000, Teresina-Brasil *emfchaves@gmail.com 2Universidade Federal do Piauí, Avenida Universitária, 1310, Campus da Ininga, CEP: 64.049-550, Teresina-Brasil

\begin{abstract}
RESUMO: O presente estudo foi realizado na Área de Proteção Ambiental da Serra da Ibiapaba no município de Cocal, Piauí. Objetivou-se realizar o levantamento das plantas utilizadas pela comunidade, das partes usadas, das indicações, das formas de uso e de administração dessas plantas. Foram realizadas 80 entrevistas com $100 \%$ dos moradores de notório saber, residentes no município que utilizavam e/ou comercializavam plantas de uso medicinal. Para definição da amostra utilizou-se o método de bola de neve. Em incursões guiadas por membros da comunidade, foram coletadas as etnoespécies citadas. Após essa etapa, as espécies foram identificadas em laboratório e calculado o Fator de Consenso dos Informantes (FCl) para cada categoria de doença. O material foi incorporado ao acervo do Herbário Graziela Barroso (TEPB/UFPI). Foram identificadas 76 espécies, distribuídas em 61 gêneros e 36 famílias. Sobresairam-se Leguminosae com 22 espécies (28,9\%), seguida por Euphorbiaceae com 6 (7,8\%), e Solanaceae $4(5,2 \%)$. Os gêneros Croton L. e Hymenaea L. obtiveram o maior destaque, somando 8 (10,5\%) do total de espécies. As espécies mais presentes nas indicações de uso foram Ximenia americana com 14 (5,9\%), Tabebuia impetiginosa com 9 (3,9\%) e Anacardium occidentale com 7 (2,9\%). Observou-se que $80,5 \%$ dos entrevistados tinham mais de 50 anos e residiam no município a mais de 20 anos, sendo que $70 \%$ possuíam apenas ensino fundamental incompleto e $20 \%$ eram analfabetos. Houve maior consenso entre os informantes para tratamento das doenças do sistema respiratório $(0,66)$ e do aparelho digestório $(0,65)$. A maioria das indicações de usos $81(34,17 \%)$ relatados para $28(36,8 \%)$ das espécies visavam curar males do sistema respiratório, tais como asma, bronquite, gripe, inflamação na garganta, pneumonia e sinusite. Para o preparo dos remédios, as partes mais utilizadas foram as cascas $(30,5 \%)$, as folhas $(29,4 \%)$ e as raízes $(12,6 \%)$. As preparações mais comuns foram os chás, garrafadas e lambedores, administrados por via oral. Os resultados sinalizaram para a importância do potencial bioativo da vegetação do carrasco.
\end{abstract}

Palavras-chave: Plantas úteis, etnobotânica, etnomedicina, semiárido

ABSTRACT: Diversity and use of medicinal resources of "carrasco" in the EPA of Serra da Ibiapaba, Piauí, Northeast Brazil. The present study was carried out in the Environmental Protection Area of Serra da Ibiapaba, in Cocal Municipality, Piauí. The study aimed to perform a survey of the plants used by the community, including used parts, recommended use, forms of use and administration of these plants. A total of 80 interviews were done with $100 \%$ of denizens with noteworthy knowledge who lived in that municipality and used and/or commercialized plants of medicinal use. To define the sample the snowball method was adopted. In tours guided by members of the community, the cited ethnospecies were collected. After this stage, the species were identified in the laboratory and the Informant Consensus Factor (ICF) was calculated for each disease category. The material was incorporated in the collection of Herbarium Graziela Barroso (TEPB/UFPI). A total of 76 species were identified, distributed into 61 genera and 36 families. Leguminosae was the major family with 22 species ( $28.9 \%)$, followed by Euphorbiaceae with $6(7.8 \%)$ and Solanaceae with $4(5.2 \%)$. Croton L. and Hymenaea L. were the most important genera, comprising $8(10.5 \%)$ of the total species. The species most commonly recommended for medicinal use were Ximenia americana with 14 (5.9\%), Tabebuia impetiginosa with 9 (3.9\%) and Anacardium occidentale with 7 (2.9\%). The age of $80.5 \%$ of the interviewees was over 50 years and they had been living in the municipality for more than 20 years, while $70 \%$ had only

Recebido para publicação em 16/05/2010

Aceito para publicação em 17/04/2012

Rev. Bras. PI. Med., Botucatu, v.14, n.3, p.476-486, 2012. 
incomplete elementary education and $20 \%$ were illiterate. There was greater consensus among the informants for treatment of respiratory diseases (0.66) and problems of the digestive system (0.65). The most common recommendation of use, $81(34.17 \%)$, reported for $28(36.8 \%)$ of the species, aimed to cure problems of the respiratory system, such as asthma, bronchitis, influenza, inflammation of the throat, pneumonia, and sinusitis. In the preparation of medicines, the parts most commonly used were the bark (30.5\%), the leaves $(29.4 \%)$ and the roots $(12.6 \%)$. The most common preparations were tea, balm and lickers, administered orally. The results indicated the importance of the bioactive potential of "carrasco" vegetation.

Key words: useful plants, ethnobotany, ethnomedicine, semiarid region

\section{INTRODUÇÃO}

O uso das plantas para aliviar os males humanos data do início da existência do homem na Terra, sendo esses hábitos e costumes tão variados entre as populações, que não se pode mais duvidar da efetiva atuação das substâncias oriundas dos vegetais (Silva, 2004).

É crescente e data de períodos longínquos o interesse de pesquisadores de diversas áreas do conhecimento em investigar as plantas citadas como detentoras de substâncias com poder de curar enfermidades. Muitos desses estudos foram realizados no Nordeste do Brasil. Dentre os pioneiros estão Braga (1960), Agra (1982, 1996), Matos (1989) e Agra \& Silva (1993). Na literatura recente a título de exemplo podem ser citados Agra et al. (2005, 2007a,b), Morais et al. (2005), Torres et al. (2005), Franco \& Barros (2006), Albuquerque et al.(2007) e Oliveira \& Araújo (2007).

A etnobotânica vem sendo influenciada pelas necessidades da etnofarmacologia e apesar de não objetivar identificar substâncias químicas com uso farmacológico, mostra potencial de desdobramento, com a indicação de espécimes, partes utilizadas, particularidades do preparo e do uso que subsidiam essa área da pesquisa (Albuquerque \& Hanazaki, 2006).

A prática do uso das plantas na medicina tradicional está incluída e reconhecida no sistema primário de saúde em países em desenvolvimento já que estes possuem $67 \%$ das espécies vegetais do mundo (MS, 2006).

Entretanto, o uso desordenado dos recursos vegetais do semiárido tem provocado grandes danos, mantendo-se menos impactadas apenas as áreas que compõem Unidades de Conservação (IBAMA, 1998). Apesar da importância etnobotânica e etnofarmacológica dessas formações vegetais, algumas ainda carecem de estudos que forneçam informações claras acerca do uso das espécies etnomedicinais. Esses estudos são de fundamental importância para a obtenção de dados confiáveis aplicáveis visando bioprospecção e para a obtenção de modelos de manejo que realmente conduzam à conservação dos recursos naturais (Albuquerque \& Andrade, 2002).
Inserida neste contexto encontra-se a vegetação caducifólia não espinhosa, denominada carrasco, que cobre extensas áreas no Planalto da Ibiapaba e Chapada do Araripe. Este trabalho teve como objetivo realizar o levantamento das partes usadas, indicações, formas de uso e administração das plantas oriundas deste tipo vegetacional e utilizadas como medicinais pela comunidade no município de Cocal, semiárido piauiense, Nordeste do Brasil, a fim de contribuir para a construção do conhecimento dos saberes populares no que concerne a etnobotânica, subsidiar a etnofarmacologia e colaborar com a conservação desse tipo vegetacional.

\section{MATERIAL E MÉTODO}

\section{Caracterização da área de estudo}

O presente estudo foi realizado no município de Cocal, Piauí, situado a $372 \mathrm{~km}$ ao norte da capital Teresina, inserido na Área de Proteção Ambiental da Serra da lbiapaba, com extensão de $1.269 \mathrm{~km}^{2}$ entre

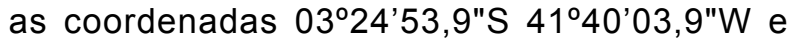
$03^{\circ} 25^{\prime} 44,9^{\prime \prime S} 41^{\circ} 21^{\prime} 27,6^{\prime \prime} \mathrm{W}$, estando a sede situada a uma altitude de $160 \mathrm{~m}$ (IBGE, 2002).

A temperatura e precipitação média anuais são de $26,6^{\circ} \mathrm{C}$ e $1.100,1 \mathrm{~mm}$, respectivamente, com maior pluviosidade nos meses de março a maio, com excedente de $271,0 \mathrm{~mm}$, e menor nos meses de julho a dezembro, podendo atingir deficiência no solo de $763,0 \mathrm{~mm}$. Segundo a classificação de Köppen, a área do município está inserida sob o domínio dos climas Aw' - Tropical, com máximos pluviométricos no verão (Medeiros, 2004).

A formação vegetal denominada carrasco se encontra distribuída em toda a área do município, em altitudes que variam de 110 m a 500 m e se caracteriza por ser caducifólia, arbustiva e possuir fisionomia densa.

A população do município é de aproximadamente 26.201 habitantes (IBGE, 2007) e mais de $50 \%$ reside em aglomerados rurais e possue como atividade econômica a agricultura familiar, a 
criação de pequenos animais, e o extrativismo.

\section{Coleta e análise dos dados}

A coleta de dados consistiu de entrevistas semiestruturadas com base em formulários, de acordo com Martin (1995). Para definição da amostragem utilizou-se o método de bola de neve segundo Albuquerque \& Lucena (2004). Foram entrevistados 80 moradores residentes perfazendo $100 \%$ dos detentores de notório saber, que utilizam e/ou comercializam etnoespécies da flora local com fins medicinais. Nessas entrevistas foram registradas as informações concernentes às partes das plantas utilizadas, indicações, formas de uso e administração com fins terapêuticos, além das informações abordando os aspectos socioeconômicos, nome, idade, naturalidade, profissão e tempo de residência do entrevistado no município. As informações obtidas passaram a nortear as coletas de amostras botânicas da flora indicada como uso medicinal, mediante procedimento rotineiro de campo (Mori et al., 1989), em incursões guiadas por membros da comunidade. (Albuquerque \& Lucena, 2004).

Para a classificação das espécies foi adotado o sistema de Cronquist (1981), exceto para Leguminosae que obedeceu a Judd et al. (1999). Os nomes e/ou abreviaturas dos nomes dos autores das espécies seguiram IPNI (2009). Todo o material identificado encontra-se incorporado ao acervo do Herbário Graziela Barroso (TEPB) da Universidade Federal do Piauí.

As informações obtidas foram agrupadas segundo a classificação das doenças da Organização Mundial da Saúde (OMS, 2000) e calculado o Fator de Consenso dos Informantes (FCl) de acordo com Trotter \& Logan (1986). Os resultados foram tabulados e discutidos a fim de mensurar a importância desses dados como instrumento norteador de pesquisas etnofarmacológicas e de bioprospecção consciente, possibilitando valorizar o conhecimento tradicional local e uso sustentável dessa vegetação.

\section{RESULTADO E DISCUSSÃO}

Em Cocal as plantas utilizadas como medicinais fazem parte da rotina no tratamento de várias doenças. A cultura popular do uso de diversas partes das plantas em preparações como chás, emplastros, garrafadas são práticas comuns e passadas de pais para filhos, no curso das gerações. Apesar desse fato, os maiores detentores das "fórmulas medicinais" na comunidade são os mais idosos. Nesse estudo, $87,5 \%$ dos informantes estavam acima dos 50 anos e residiam no município ha mais de 20 anos, corroborando com os resultados de Franco \& Barros (2006), que ao estudarem o uso das plantas medicinais no Quilombo Olho D'água dos
Pires, Esperantina $(\mathrm{PI})$, relataram que mais da metade das informações foram fornecidas por pessoas com mais de 50 anos.

Quanto aos aspectos socioeconômicos, $70 \%$ dos entrevistados possuem ensino fundamental incompleto, enquanto $10 \%$ sabem ler e $20 \%$ são analfabetos; $52 \%$ têm renda familiar maior que um e menor que dois salários mínimos, $26 \%$ somam entre dois e três salários, $12 \%$ percebem mensalmente valores inferiores a um salário e apenas $10 \%$ referiram rendas superiores a três salários mínimos; $100 \%$ habitam em casas cobertas de telhas, das quais $94 \%$ são construídas de tijolos com reboco, $4 \%$ são casas de tijolos sem reboco e $2 \%$ de pau-a-pique; $92 \%$ dos entrevistados abastecem suas casas com água procedente de poços e os $8 \%$ restantes utilizam fontes diversas como olhos-d'água, açudes, rios e riachos a depender da disponibilidade; $48 \%$ possuem fossas sépticas, $28 \%$ não possuem qualquer saneamento, liberando os dejetos a céu aberto e $24 \%$ referiram a utilização de fossa negra.

A análise dos dados socioeconômicos e da relação da comunidade com a vegetação do carrasco conduz ao entendimento de que esse recurso é significativo para o bem estar dessas famílias, uma vez que a maioria pratica agricultura de subsistência desassistida, exposta à sazonalidade e às intempéries, comuns na zona rural do semiárido e depende do carrasco para prover os meios necessários para tratar seus males. Boff (2008), ao estudar o comportamento da sociedade humana no que concerne à responsabilidade ambiental, entendeu que as sociedades estão enfermas, produzem má qualidade de vida para todos os seres humanos e demais seres da natureza. Esse entendimento reforça o pensamento no sentido de preservar os saberes populares de convivência e uso da biodiversidade natural.

A partir do inquérito etnomedicinal das plantas utilizadas na comunidade foram identificadas 76 espécies, distribuídas em 61 gêneros e 36 famílias (Tabela 1). As famílias com maior número de espécies citadas foram Leguminosae com $22(28,9 \%)$, seguida por Euphorbiaceae com $6(7,8 \%)$, e Solanaceae 4 $(5,2 \%)$. Os gêneros Croton L. e Hymenaea L. com quatro espécies cada somaram $8(10,5 \%)$ do total de espécies. As famílias Leguminosae e Euphorbiaceae também se destacaram em Abreu (2000) e segundo Souza (2007), o destaque para Leguminosae entre as plantas de uso medicinal pode ser explicado pelo grande número e diversidade de espécies que compõem esta família.

Os informantes forneceram 237 indicações de uso em 15 categorias de doenças, sendo que apresentaram maior consenso entre os mesmos, aquelas indicações relativas ao tratamento das doenças do sistema respiratório $(0,66)$ e do aparelho

Rev. Bras. PI. Med., Botucatu, v.14, n.3, p.476-486, 2012. 
TABELA 1. Lista das famílias, nomes científicos e populares das espécies etnomedicinais citadas pelos moradores do município de Cocal, Piauí. Convenção: NR: número de registro no TEPB.

\begin{tabular}{|c|c|c|c|}
\hline $\begin{array}{l}\text { Família/nome científicol } \\
\text { nome popular }\end{array}$ & $\begin{array}{l}\text { Parte } \\
\text { usada }\end{array}$ & $\begin{array}{l}\text { Indicação e } \\
\text { forma de uso }\end{array}$ & NR \\
\hline \multicolumn{4}{|l|}{ Amaranthaceae } \\
\hline $\begin{array}{l}\text { Alternanthera brasiliana (L.) Kuntze } \\
\text { Quebra-panela }\end{array}$ & Flores & $\begin{array}{l}\text { Infusão para inalação de vapores pela manhã e a noite como } \\
\text { descongestionante nasal em gripes e sinusites. }\end{array}$ & 20.099 \\
\hline $\begin{array}{l}\text { Gomphrena demissa Mart. } \\
\text { Capitãozinho }\end{array}$ & Raízes & $\begin{array}{l}\text { Garrafada duas vezes ao dia contra inflamações de útero e ovários } \\
\text { e para aumentar a fertilidade feminina. }\end{array}$ & 19.128 \\
\hline \multicolumn{4}{|l|}{ Anacardiaceae } \\
\hline $\begin{array}{l}\text { Anacardium occidentale L. } \\
\text { Cajuí }\end{array}$ & $\begin{array}{l}\text { Caule } \\
\text { (cascas), } \\
\text { folhas, resinas }\end{array}$ & $\begin{array}{l}\text { Infusão das folhas contra dor na barriga e diarréia três vezes ao } \\
\text { dia; cascas em lambedor oferecido livremente e banho de infusão } \\
\text { para bronquite, gripe e pneumonia; garrafada antes de dormir } \\
\text { contra derrame; emplastro de resina para cicatrizar ferimento. }\end{array}$ & 20.249 \\
\hline $\begin{array}{l}\text { Myracrodruon urundeuva Allem. } \\
\text { Aroeira }\end{array}$ & Caule (cascas) & $\begin{array}{l}\text { Garrafada contra inflamação três vezes ao dia e o decocto no } \\
\text { combate a gastrite e úlcera quando sentir dor. }\end{array}$ & 19.158 \\
\hline $\begin{array}{l}\text { Spondias lutea L. } \\
\text { Cajá }\end{array}$ & Folhas & Infusão como constipante contra diarréia e dor na barriga. & 20.237 \\
\hline
\end{tabular}

Ata-de-urubu

\section{Apocynaceae}

Aspidosperma subincanum Mart.

Folhas

Infusão depois de refeições de difícil digestão.

20.046

Pequiá

\section{Arecaceae}

Astrocaryum vulgare Mart. Frutos

Frutos Consumido in natura em quantidades livres no tratamento de

20.235

Tucum inflamação nos olhos (terçol).

Copernicia prunifera (Mill.) H.E.Moore Raízes

Garrafada três vezes ao dia para combater diarréia, dor na barriga,

20.234

Carnaubeira sífilis e doenças na pele.

\section{Bignoniaceae}

Tabebuia impetiginosa (Mart.) Standl. Caule (cascas) Decocto consumido livremente e garrafada três vezes ao dia no

Pau-d'arco-roxo controle da anemia, sangue grosso, inflamação de ouvido, dor no corpo, picada de cobra, sinusite, afta, diarréia, úlcera e câncer.

T. serratifolia G.Nicholson

Caule (cascas) Macerado com água, tomado quando sentir sede por duas semanas,

Pau-d'arco-amarelo contra cancro, doenças renais, hepáticas e dos intestinos.

\section{Boraginaceae}

Cordia rufescens A.DC. Infusão uma vez ao dia como calmante

Grão-de-galo

Heliotropium polyphyllum Lehm. Raízes Garrafada como depurativo do sangue e para tratar inflamação.

20.337

Sete-sangrias

\section{Bromeliaceae}

Bromelia laciniosa Mart. ex Schult. Raízes

Raízes de molho em água fria para beber quando tiver sede, no

19.133

Macambira-miúda tratamento de hepatite, cirrose, diarréia, dor na barriga, gastrite e como diurético até desaparecerem os sintomas.

\section{Cactaceae}

Cereus jamacaru DC.

Mandacaru

\section{Capparaceae}

Cleome aculeata L.

Muçambê

\section{Combretaceae}

Combretum leprosum Mart.

Mofumbo

Caule (polpa) Infusão usada livremente no combate a inflamação, males dos

18.198 rins, hepatite e cirrose.

Folhas, raízes Lambedor tomado como xarope quatro vezes ao dia contra gripe, $\quad 18.788$ tosse e bronquite.

Caule (cascas) Decocto três vezes ao dia no controle de dor na barriga e diarréia; banho de assento duas vezes ao dia no tratamento de hemorróidas; 
TABELA 1. Lista das famílias, nomes científicos e populares das espécies etnomedicinais citadas pelos moradores do município de Cocal, Piauí. Convenção: NR: número de registro no TEPB.

\begin{tabular}{|c|c|c|c|}
\hline $\begin{array}{l}\text { Família/nome científicol } \\
\text { nome popular }\end{array}$ & $\begin{array}{l}\text { Parte } \\
\text { usada }\end{array}$ & $\begin{array}{l}\text { Indicação e } \\
\text { forma de uso }\end{array}$ & NR \\
\hline & & $\begin{array}{l}\text { emplastro para parar hemorragia e garrafada cinco vezes ao dia } \\
\text { contra inflamação. }\end{array}$ & \\
\hline \multicolumn{4}{|l|}{ Chrysobalanaceae } \\
\hline $\begin{array}{l}\text { Licania rigida Benth. } \\
\text { Oiticica }\end{array}$ & Folhas & Infusão em água ingerida três vezes ao dia no tratamento de diabetes. & 20.233 \\
\hline $\begin{array}{l}\text { Euphorbiaceae } \\
\text { Cnidoscolus urens Arthur }\end{array}$ & Caule (cascas) & $\begin{array}{l}\text { Garrafada tomada em substituição a água quando tiver sede no } \\
\text { combate a inflamação de ovários e próstata. }\end{array}$ & 20.224 \\
\hline $\begin{array}{l}\text { Cansanção } \\
\text { Croton blanchetianus Baiil. }\end{array}$ & Folhas & $\begin{array}{l}\text { Infusão três vezes ao dia no combate a inchaço, dor na barriga e } \\
\text { diarréia. }\end{array}$ & 19.178 \\
\hline $\begin{array}{l}\text { Marmeleiro } \\
\text { C. campestris A.St.-Hil. }\end{array}$ & $\begin{array}{l}\text { Caule (cascas), } \\
\text { folhas }\end{array}$ & $\begin{array}{l}\text { Decocto da folha ou da casca três vezes ao dia no controle de dores } \\
\text { em geral e gripe, bronquite, pneumonia e asma. }\end{array}$ & 18.780 \\
\hline $\begin{array}{l}\text { Velame-cabeludo } \\
\text { C. rhamnifolius Kunth }\end{array}$ & Folhas & $\begin{array}{l}\text { Infusão sem açúcar administrada livremente no tratamento de diabetes } \\
\text { e em garrafada contra inflamação. }\end{array}$ & 20.325 \\
\hline Velame & Folhas & Infusão ingerida antes de dormir alivia a inquietação. & 18.768 \\
\hline
\end{tabular}

C. zehntneri Pax \& K.Hoffm.

Folhas, raízes Infusão das folhas três vezes ao dia contra gripe, pneumonia,

Phyllanthus niruri L. fígado e nos rins.

Flacourtiaceae

Casearia sylvestris Sw.

Folhas

Infusão e emplastro contra veneno de cobra.

Língua-de-tio

\section{Lamiaceae}

Hyptis suaveolens (L.) Poit. $\quad$ Folhas

Infusão após refeições de difícil digestão.

Bamburral

Leonotis nepetifolia Schimp. ex Folhas

Benth.

Infusão consumida três vezes ao dia no tratamento de infecção 18.839

Cordão-de-são-francisco

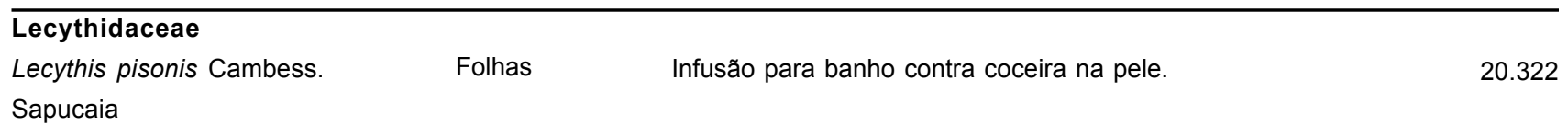

Leguminosae

\section{Caesalpinioideae}

Bauhinia cheilantha (Bong.) D.Dietr. Folhas, caule Decocto sem açúcar no combate a diabetes e a garrafada da casca Mororó

(cascas)

para tratar diabetes e inflamação.

B. ungulata L.

Folhas, caule

Infusão sem açúcar no tratamento de diabetes e a garrafada da

18.794

Mororó

(cascas)

casca no combate a diabetes e a inflamação.

Caesalpinia bracteosa Tul.

Folhas

Infusão duas vezes ao dia para combater gases e má digestão.

20.222

Catingueira

C. ferrea Mart.

Jucá

Caule (cascas), Decocto, garrafada e lambedor com casca e/ou fruto e/ou semente em

frutos, sementes três doses diárias contra sinusite, dor na garganta, depurativo do sangue, resguardo quebrado, doença de mulher, inchaço e ferimento na pele.

Copaifera martii Hayne Caule (óleo)

Uma colherada de óleo misturado com mel ou em lambedor antes de dormir

Podoi contra gripe, bronquite, pneumonia, constipação, inflamação e câncer. Garrafada do caule e flores consumida livremente conta gripe, sinusite,

Hymenaea courbaril L. Caule (cascas), bronquite e inflamação e resina na forma de emplastro para cicatrizar 
TABELA 1. Lista das famílias, nomes científicos e populares das espécies etnomedicinais citadas pelos moradores do município de Cocal, Piauí. Convenção: NR: número de registro no TEPB.

continuação...

\begin{tabular}{|c|c|c|}
\hline $\begin{array}{l}\text { Família/nome científicol } \\
\text { nome popular }\end{array}$ & $\begin{array}{l}\text { Parte } \\
\text { usada }\end{array}$ & $\begin{array}{l}\text { Indicação e } \\
\text { forma de uso }\end{array}$ \\
\hline $\begin{array}{l}\text { H. martiana Hayne } \\
\text { Jatobai }\end{array}$ & Caule (cascas) & $\begin{array}{l}\text { Garrafada ou lambedor três vezes ao dia contra gripe, sinusite, } \\
\text { bronquite e inflamação. }\end{array}$ \\
\hline $\begin{array}{l}\text { H. stigonocarpa Mart. ex Hayne } \\
\text { Jatobá }\end{array}$ & Caule (cascas) & $\begin{array}{l}\text { Lambedor com mel de abelha uma colherada antes de dormir contra } \\
\text { tosse, bronquite e inflamação de garganta. }\end{array}$ \\
\hline $\begin{array}{l}\text { Senna occidentalis (L.) Link } \\
\text { Mangirioba }\end{array}$ & Folhas, flores & $\begin{array}{l}\text { Infusão da folha antes de dormir contra gripe, resfriado, dor na } \\
\text { garganta, dor na cabeça e emplastro com macerado de folhas contra } \\
\text { impingem. }\end{array}$ \\
\hline $\begin{array}{l}\text { S. spectabilis (DC.) H.S.Irwin \& } \\
\text { Barneby }\end{array}$ & Caule (cascas) & Decocto ou lambedor antes de dormir no combate a gripes e sinusites. \\
\hline Flor-de-besouro & & \\
\hline $\begin{array}{l}\text { S. trachypus (Benth.) H.S.Irwin \& } \\
\text { Barneby }\end{array}$ & Folhas, flores & $\begin{array}{l}\text { Infusão das folhas sem açúcar no combate a diabetes e das flores } \\
\text { uma vez ao dia contra bronquite, rouquidão, reumatismo, inflamação. }\end{array}$ \\
\hline
\end{tabular}

Flor-de-besouro

Mimosoideae

Acacia farnesiana Wall.

Coronha

Folhas, flores,

Infusão ou garrafada de qualquer das partes antes de dormir contra

18.835

febre, gripe, dor na garganta, diarréia, dor na barriga e dor na cabeça e lambedor de flores e/ou sementes três vezes ao dia no combate a gripe e rouquidão.

Mimosa acutistipula Benth.

Caule (cascas)

Infusão duas vezes ao dia no combate a diarréia, dor na barriga, dor de cabeça e insônia.

Catanduva-branca

Caule (cascas) Lambedor com mel como expectorante no combate a gripe, catarro no peito, rouquidão e dor na garganta.

Sabiá

M. hostilis Benth.

Raízes

Garrafada três vezes ao dia para tratar hepatite, gastrite e úlcera.

Jurema

Piptadenia moniliformis Benth.

Caule (cascas)

Infusão antes de dormir como digestivo e depurativo e emplastro no tratamento de furúnculo.

Rama-de-bezerro

\section{Papilionoideae}

Amburana cearensis (Fr.Allem.)

A.C.Sm.

Caule (cascas), sementes

Imburana-de-cheiro

Bowdichia virgilioides Kunth

Sucupira

Caule (cascas), sementes

Dioclea grandiflora Mart. ex Benth. Látex (seiva)

Mucunã

Pterocarpus vilosus Mart.

Flores

Pau-sangue

Swartzia flaeminggi var.

Folhas, caule

(cascas)

Garrafada da casca e sementes em três doses diárias como antiabortivo e depurativo do sangue e no tratamento de inflamação na garganta, sinusite, bronquite.

psilonema (Harms) Cor.

Jacarandá

\section{Malpighiaceae}

Byrsonima gardneriana A.Juss.

Murici-de-chapada

Frutos

In natura dez frutos consumidos diariamente para retardar o

18.828

\section{Malvaceae}

Sida cordifolia L.

Folhas envelhecimento.

Malva-branca

\section{Meliaceae}

Cedrela odorata L.

Cedro
Garrafada das cascas e sementes no combate a gripe, dor na garganta, rouqidão dor na cabeça e inflamação.

Garrafada com gotas do látex em uma dose diária contra gripe e dor na garganta.

Infusão nos intervalos das refeições para combater a fraqueza e aumentar a disposição.

Garrafada três vezes ao dia no tratamento de reumatismo, dor nas articulações e doenças hepatite e cirrose. 
TABELA 1. Lista das famílias, nomes científicos e populares das espécies etnomedicinais citadas pelos moradores do município de Cocal, Piauí. Convenção: NR: número de registro no TEPB.

continuação...

\begin{tabular}{lll}
\hline $\begin{array}{l}\text { Família/nome científicol } \\
\text { nome popular }\end{array}$ & $\begin{array}{l}\text { Parte } \\
\text { usada }\end{array}$ & $\begin{array}{l}\text { Indicação e } \\
\text { forma de uso }\end{array}$ \\
\hline
\end{tabular}

\section{Myrtaceae}

$\begin{array}{lll}\text { Campomanesia aromatica (Aubl.) } & \begin{array}{l}\text { Folhas do olho Infusão vezes ao dia contra diarréia, dor na barriga, catarro no peito, } \\ \text { da planta }\end{array} & \begin{array}{l}18.826 \\ \text { Gneumonia, gripe. }\end{array}\end{array}$

Guabiraba

C. flavescens DC. $\quad$ Folhas $\quad$ Banho com a infusão uma vez ao dia no combate a febre.

20.240

Maria-preta

20.239

Farinha-seca

\section{Olacaceae}

Ximenia americana L.

Caule (cascas) Garrafada três vezes ao dia contra dor na garganta, pneumonia,

Ameixa-amarela

bronquite, Inflamação, depurativo do sangue, inflamação de ovários,

dos olhos, dos ouvidos, reumatismo, câncer; na forma de pó seco

como anti-séptico para cicatrizar ferimento; banho de assento para

hemorróida duas vezes ao dia.

\begin{tabular}{|c|c|c|c|}
\hline \multicolumn{4}{|l|}{ Passifloraceae } \\
\hline $\begin{array}{l}\text { Passiflora cincinnata Mast. } \\
\text { Maracujá-do-mato }\end{array}$ & Frutos & $\begin{array}{l}\text { Suco consumido antes de dormir três vezes por semana alivia a } \\
\text { insônia. }\end{array}$ & 19.250 \\
\hline \multicolumn{4}{|l|}{ Portulacaceae } \\
\hline \multicolumn{4}{|l|}{ Bredo } \\
\hline \multicolumn{4}{|l|}{ Rhamnaceae } \\
\hline $\begin{array}{l}\text { Ziziphus joazeiro Mart. } \\
\text { Juazeiro }\end{array}$ & $\begin{array}{l}\text { Caule (cascas e } \\
\text { pó das cascas), } \\
\text { frutos }\end{array}$ & $\begin{array}{l}\text { Garrafada da casca e/ou in natura cinco frutos duas vezes ao dia } \\
\text { contra asma, bronquite, gripe, pneumonia, gastrite, úlcera, afta e má } \\
\text { digestão; o pó da casca como anti-séptico em ferimentos na pele. }\end{array}$ & 20.558 \\
\hline \multicolumn{4}{|l|}{ Rubiaceae } \\
\hline $\begin{array}{l}\text { Genipa americana L. } \\
\text { Jenipapo }\end{array}$ & Caule (cascas) & Emplastro com raspas da casca conta desmentidura (luxação). & 19.764 \\
\hline $\begin{array}{l}\text { Guettarda viburnoides Cham. } \\
\text { \& Schltdl. } \\
\text { Angélica-do-mato }\end{array}$ & Raízes & Decocto quando surgirem cólicas menstruais. & 19.173 \\
\hline \multicolumn{4}{|l|}{ Sapotaceae } \\
\hline $\begin{array}{l}\text { Tocoyena formosa K. Schum. } \\
\text { Jeniparama }\end{array}$ & Caule (cascas) & Emplastro com raspas da casca conta desmentidura (luxação). & 20.320 \\
\hline $\begin{array}{l}\text { Pouteria ramiflora Radlk. } \\
\text { Pitomba-de-leite }\end{array}$ & Látex & $\begin{array}{l}\text { Emplastro com o látex em algodão sobre machucados que não abriram } \\
\text { a pele. }\end{array}$ & 19.047 \\
\hline \multicolumn{4}{|l|}{ Sapindaceae } \\
\hline $\begin{array}{l}\text { Talisia esculenta Radlk. } \\
\text { Pitomba-de-macaco }\end{array}$ & $\begin{array}{l}\text { Folhas, caule } \\
\text { (cascas) }\end{array}$ & Infusão uma vez ao dia no combate às cólicas menstruais. & 20.236 \\
\hline \multicolumn{4}{|l|}{ Scrophulariaceae } \\
\hline $\begin{array}{l}\text { Scoparia dulcis } L \text {. } \\
\text { Vassourinha }\end{array}$ & Raízes & $\begin{array}{l}\text { Lambedor livremente contra gripe, sinusite, bronquite e garrafada } \\
\text { três vezes ao dia no combate a inflamação. }\end{array}$ & 19.245 \\
\hline \multicolumn{4}{|l|}{ Solanaceae } \\
\hline $\begin{array}{l}\text { Physalis angulata L. } \\
\text { Canapum }\end{array}$ & Frutos & $\begin{array}{l}\text { Cinco frutos in natura duas vezes ao dia no intervalo das refeições } \\
\text { no combate ao câncer. }\end{array}$ & 18.189 \\
\hline $\begin{array}{l}\text { Solanum crinitum Lam. } \\
\text { Jurubeba }\end{array}$ & Fruto & $\begin{array}{l}\text { Decocto frio duas vezes por semana para lavar impinjens quando } \\
\text { não houver ferimento na pele. }\end{array}$ & 18.852 \\
\hline $\begin{array}{l}\text { S. paniculatum L. } \\
\text { Jurubeba-branca }\end{array}$ & Caule (cascas) & $\begin{array}{l}\text { Emplasto com macerado da casca sobre o furúnculo quando a pele } \\
\text { não estiver aberta. }\end{array}$ & 19.168 \\
\hline
\end{tabular}

Rev. Bras. PI. Med., Botucatu, v.14, n.3, p.476-486, 2012. 
TABELA 1. Lista das famílias, nomes científicos e populares das espécies etnomedicinais citadas pelos moradores do município de Cocal, Piauí. Convenção: NR: número de registro no TEPB.

\begin{tabular}{|c|c|c|c|}
\hline $\begin{array}{l}\text { Família/nome científicol } \\
\text { nome popular }\end{array}$ & $\begin{array}{l}\text { Parte } \\
\text { usada }\end{array}$ & $\begin{array}{l}\text { Indicação e } \\
\text { forma de uso }\end{array}$ & $\mathbf{N R}$ \\
\hline $\begin{array}{l}\text { S. paludosum Moric. } \\
\text { Jurubeba }\end{array}$ & Raízes & $\begin{array}{l}\text { Infusão uma colher duas vezes por semana no tratamento } \\
\text { hepatite, cirrose e verminoses. }\end{array}$ & 19.168 \\
\hline \multicolumn{4}{|l|}{ Tiliaceae } \\
\hline $\begin{array}{l}\text { Luehea candicans Mart. } \\
\text { Açoita-cavalo }\end{array}$ & Caule (cascas) & $\begin{array}{l}\text { Garrafada três vezes ao dia contra gripe, dor na garganta, } \\
\text { pneumonia, anemia, hepatite, cirrose, câncer, como depurativo } \\
\text { do sangue e para tratar inflamação. }\end{array}$ & 18.847 \\
\hline \multicolumn{4}{|l|}{ Turneraceae } \\
\hline $\begin{array}{l}\text { Piriqueta racemosa Sweet } \\
\text { Malva-de-vassoura }\end{array}$ & Planta inteira & $\begin{array}{l}\text { Garrafada antes de dormir para regular o fluxo menstrual. } \\
\text { Considerado abortivo. }\end{array}$ & 19.172 \\
\hline \multicolumn{4}{|l|}{ Verbenaceae } \\
\hline $\begin{array}{l}\text { Lantana camara L. } \\
\text { Chumbinho }\end{array}$ & Folhas & $\begin{array}{l}\text { Infusão duas vezes ao dia como diurético e expectorante em } \\
\text { gripes e pneumonias }\end{array}$ & 19.160 \\
\hline \multicolumn{4}{|l|}{ Violaceae } \\
\hline $\begin{array}{l}\text { Hybanthus communis Taub. } \\
\text { Ipecacoanha }\end{array}$ & Raízes & Lambedor como diurético e expectorante & 19.202 \\
\hline \multicolumn{4}{|l|}{ Vitaceae } \\
\hline $\begin{array}{l}\text { Cissus erosa Rich. } \\
\text { Cipó-de-fogo }\end{array}$ & Partes aéreas & $\begin{array}{l}\text { Infusão duas vezes ao dia como analgésico no tratamento de } \\
\text { leishmaniose. }\end{array}$ & 19.052 \\
\hline
\end{tabular}

digestório $(0,65)$, seguidas por doenças do sistema circulatório $(0,44)$ e ainda as do sistema genitourinário com 0,22 (Tabela 2). Maioli-Azevedo \& Fonseca-Kruel (2007) ao estudarem as plantas medicinais vendidas em feiras livres no Rio de Janeiro (RJ), observaram que as categorias de uso que apresentam maiores valores de consenso são culturalmente importantes e merecem estudos mais aprofundados das espécies e usos adotados.

Segundo Trotter \& Logan (1986), há maior consenso entre os informantes quando uma espécie é indicada por vários informantes para sinais e sintomas de uma categoria de doença, por essa razão, aparecem com menores valores de consenso, as categorias para as quais são utilizadas diversas espécies e com vários usos, como por exemplo, o grupo de sintomas e sinais gerais com $23(30,2 \%)$ das espécies e $24(10,1 \%)$ das indicações de uso e com fator de consenso de apenas 0,04 (Tabela 2). Esses dados são similares aos encontrados por Maioli-Azevedo \& Fonseca-Kruel (2007) que indicaram a possibilidade de supervalorização de determinadas categorias devido ao baixo número de citações e espécies envolvidas.

As espécies que mais se destacaram em indicações de uso medicinal no carrasco foram Ximenia americana com 14 (5,9\%), Tabebuia impetiginosa com 9 (3,9\%) e Anacardium occidentale com $7(2,9 \%)$ dos usos referidas pelos informantes. Segundo Brasileiro et al. (2008), Ximenia americana ainda é pouco investigada cientificamente, mas mostrou potencialidade para fins terapêuticos em ensaios de interesse da tecnologia farmacológica e é bastante utilizada na medicina popular, principalmente no Brasil, Nigéria e África do Sul. Araújo et al. (2007) citam ensaios pré-clínicos que mostraram a ação antitumoral de T. impetiginosa e Silva et al. (2007) comprovaram, a partir de ensaios fitoquímicos, a atividade antimicrobiana de $A$. occidentale e sugeriram mais estudos, uma vez que a espécie apresenta vários usos difundidos na cultura popular.

A maioria das indicações de usos 81 $(34,17 \%)$ relatados para $28(36,8 \%)$ das espécies visavam curar males do sistema respiratório com fator de consenso igual a 0,66 (Tabela 2), tais como asma, bronquite, gripe, inflamação na garganta, pneumonia e sinusite (Tabela 1) resultados corroborados por Silva (2003) que ao estudar a etnobotânica dos índios fulniô, Águas Belas (PE), encontrou consenso 0,87 para os transtornos do sistemas respiratório quanto a efetividade das espécies mais citadas e por Franco \& Barros (2006) em Olhos D'água dos Pires com muitas espécies indicadas para gripe, sinusite, inflamação de garganta, pneumonia, asma e tosse.

$\mathrm{Na}$ segunda posição figuram $48(14,6 \%)$ indicações de uso para 17 (22,3\%) espécies utilizadas no tratamento das doenças do sistema digestório com 0,65 do consenso dos informantes. Sendo que os usos que mais se destacaram foram para dor de barriga e diarréia. Categoria também referida com ênfase por Silva (2003), que encontrou 0,80 de 
TABELA 2. Consenso dos informantes do município de Cocal, Piauí, Brasil, para uso das plantas medicinais. Convenção: $\mathrm{FCl}$ = fator de consenso dos informantes.

\begin{tabular}{lccc}
\hline \multicolumn{1}{c}{ Categorias de doenças } & $\begin{array}{c}\text { Número de } \\
\text { espécies usadas }\end{array}$ & $\begin{array}{c}\text { Número de } \\
\text { usos citados }\end{array}$ & FCl \\
\hline Distúrbios do sistema nervoso & 4 & 5 & 0,25 \\
Distúrbios endócrinos, nutricionais e metabólicos & 7 & 7 & 0 \\
Doenças de pele e tecido celular subcutâneo & 18 & 19 & 0,05 \\
Doenças do aparelho respiratório & 28 & 81 & 0,66 \\
Doenças do sistema digestório & 17 & 48 & 0,65 \\
Doenças do sistema genitourinário & 14 & 18 & 0,22 \\
Doenças do sistema musculoesquelético & 5 & 5 & 0 \\
Doenças infectocontagiosas e parasitárias & 3 & 3 & 0 \\
Doenças nos olhos e anexos & 2 & 2 & 0 \\
Doenças nos ouvidos & 2 & 2 & 0 \\
Doenças do sistema circulatório & 6 & 10 & 0,44 \\
Lesões de envenenamento e algumas outras consequências & 2 & 2 & 0 \\
Neoplasias & 4 & 3 & 0 \\
Sangue e órgãos hematopoéticos e transtornos imunitários & 4 & 5 & 0,25 \\
Sintomas e sinais gerais & 23 & 24 & 0,04 \\
\hline
\end{tabular}

consenso com os índios fulni-ô.

Ocuparam a terceira posição as doenças do sistema circulatório com $10(4,2 \%)$ indicações e 6 $(7,8 \%)$ espécies referenciadas. A importância das espécies medicinais para o tratamento das afecções desse sistema atingiu 0,44 do consenso dos informantes e corrobora com os resultados de Almeida \& Albuquerque (2002), que ao estudarem o uso e conservação de plantas medicinais em Caruaru $(\mathrm{PE})$, encontraram resultados significativos para os transtornos do sistema circulatório $(0,53)$.

O uso das plantas do carrasco para fins terapêuticos passa por verdadeiros rituais culturais em que são considerados cuidados, tais como a época do ano (estação) em que deve ser colhida e qual parte deve ser utilizada. Auricchio \& Bacchi (2003), ao estudarem as propriedades farmacobotânicas de folhas de Eugenia uniflora L., observaram que a concentração de princípios ativos da planta pode variar em função dos diferentes períodos do dia ou épocas do ano e Bezerra et al. (2008), ao estudarem a produção e composição química da Egletes viscosa (L.) Less. em função da época de colheita, relataram que existem padrões distintos de variação dos componentes químicos da planta ao longo do ano. Achados que reforçam a importância das práticas adotadas pela comunidade.

Para o preparo dos remédios, as partes mais citadas foram as cascas retiradas dos caules $(30,5 \%)$, as folhas $(29,4 \%)$ e as raízes $(12,6 \%)$. Frutos e flores $(12,6 \%)$ cada, látex juntamente com resina e toda a parte aérea $(4,2 \%)$, além de óleo e polpa do caule $(2,1 \%)$ estiveram menos presentes no relato das preparações. As razões apontadas pelos informantes para essa preferência passam pela eficácia nos tratamentos e pela facilidade de obtenção e armazenamento. Albuquerque \& Andrade (2002) estudaram o conhecimento botânico tradicional em Alagoinha (PE) e destacaram o uso das cascas em comunidades da caatinga por estas partes estarem disponíveis durante todo o ano. Costa-Neto \& Oliveira (2000) ao estudarem as plantas medicinais em Tanquinho (BA) relataram as folhas como preferidas, dentre as partes das plantas, para uso medicinal, possivelmente devido a praticidade de preparo na forma de chás. No entanto, para Castellucci et al. (2000), que estudaram as plantas medicinais utilizadas pela comunidade da Estação Ecológica de Jataí, (SP) o uso preferencial das folhas deve-se ao efeito mais eficiente devido possuir maior concentração de princípios ativos.

No que se refere ao preparo da planta para uso medicinal, são considerados importantes o estado de saúde de quem prepara e os detalhes antes do consumo, tais como: o tempo que deve ficar em fervura ou em água quente, o repouso abafado ou destampado, se refrigerada ou à temperatura ambiente, se dentro da residência ou no chuvisco (ao ar livre fora da residência), e assim por diante. Segundo os informantes, se não forem verificadas essas variáveis, o tratamento pode não atingir os fins desejados. Annichino et al. (1986) corroboram com 
esses cuidados, pois ao estudarem a medicina caseira em Bauru (SP) concluiram, que a formulação correta dos remédios é fator indispensável para a eficácia do tratamento.

Quanto às formas de uso (Tabela 1), os chás obtiveram maior destaque, sendo preparados com partes do vegetal imersas em água e submetidas à fervura durante pouquíssimo tempo (decocto) ou na forma de infusões, onde partes da planta são cobertas por água fervente e abafadas por alguns minutos; em seguida, vieram as garrafadas com partes de um ou mais vegetais curtidos em água, cachaça ou álcool por sete dias; lambedores feitos com vegetais submetidos ao cozimento para extração do sumo (suco) e adicionado mel e emplastros que são obtidos com macerado em forma de pasta de parte selecionada de uma planta. Arnous et al. (2005) estudaram as plantas medicinais de uso caseiro em Datas (MG) e relataram que o chá é forma de preparo mais comum e constitui prática inadequada, pois provoca a perda de princípios ativos importantes. Segundo os autores, somente as partes mais duras, como raiz, caule e cascas, devem ser cozidas. Observação esta que valida a preocupação dos informantes com o tempo de fervura das folhas, levando-os a preferirem mais a infusão ao decocto.

A via oral foi a preferida para a administração das "fórmulas" medicinais, estando fortemente vinculada aos tratamentos dos males de todos os sistemas, além dos sinais e sintomas gerais. $\mathrm{O}$ uso tópico, utilizando emplastros, esteve associado principalmente ao tratamento de doenças da pele, do tecido subcutâneo e do sistema músculoesquelético, enquanto as inalações foram mais relatadas nas afecções do sistema respiratório. Resultados semelhantes foram obtidos por Monteles \& Pinheiro (2007) no Quilombo Sangrador, Presidente Juscelino (MA) onde $87,3 \%$ das citações de uso oral foram para chás utilizados no tratamento das afecções do sistema digestivo, seguidos por uso tópico através de massagens, fricções e emplastros para manchas e irritações na pele e por inalações associadas à cura dos males respiratórios.

Cientes dos dados ora analisados, concluímos que as 76 espécies etnomedicinais relatadas nesse trabalho e suas particularidades de uso sinalizam para o potencial bioativo da vegetação do carrasco; que essa vegetação é importante para a qualidade de vida e alivio dos males da comunidade local; que para a maioria das espécies identificadas não há na literatura dados sobre investigações quanto às propriedades químicas e/ou atividade biológica, e que esse estudo enfatiza a importância de investigações acerca das espécies do carrasco que são utilizadas com fins medicinais e que ainda não tenham sido estudadas em suas propriedades farmacológicas.

\section{AGRADECIMENTO}

À comunidade do município de Cocal, pelo aprendizado, amizade e colaboração espontânea e sempre valiosa, no repasse preciso das informações guardadas ao longo das suas histórias familiares e que tornaram possível a realização desse trabalho.

\section{REFERÊNCIA}

ABREU, J.R. Diversidade de recursos vegetais do cerrado utilizados pelos quilombolas Mimbó (Amarante, Piauí, Brasil). 2000. 68p. Dissertação (Mestrado-Botânica) - Universidade Federal de Pernambuco, Recife.

AGRA, M.F. Contribuição ao estudo das plantas medicinais na Paraíba. Ciência e Cultura, v.33, supl., p.64-6, 1982.

AGRA, M.F.; SILVA, M.G. Plantas medicinais usadas como cosméticos na Paraíba (Brasil) e na literatura. Revista Brasileira de Farmacognosia, v.74, n.2, p.42-4, 1993. AGRA, M.F. Plantas da medicina popular dos Cariris Velhos, Paraíba, Brasil: espécies mais comuns. João Pessoa: Editora União, 1996. 125p.

AGRA, M.F. et al. Medicinais e produtoras de princípios ativos. In: SAMPAIO, E.V.S.B. et al. (Eds.). Espécies da flora nordestina de importância econômica potencial. Recife: Associação Plantas do Nordeste, 2005, p.13598.

AGRA, M.F. et al. Medicinal and poisonous diversity of the flora of "Cariri Paraibano", Brazil. Journal of Ethnopharmacology, v.111, n.2, p.383-95, 2007a.

AGRA, M.F. et al. Synopsis of the plants known as medicinal and poisonous in Northeast of Brazil. Brazilian Journal of Pharmacognosy, v.17, n.4, p.114-40, 2007b. ALBUQUERQUE, U.P.; ANDRADE, L.H.C. Conhecimento botânico tradicional e conservação em uma área de caatinga no estado de Pernambuco, Nordeste do Brasil. Acta Botanica Brasilica, v.16, n.3, p.273-85, 2002.

ALBUQUERQUE, U.P.; LUCENA, R.F.P. Métodos e técnicas de pesquisa etnobotânica. Reccife: NUPPEA, 2004. 189p.

ALBUQUERQUE, U.P.; HANAZAKI, N. As pesquisas etnodirigidas na descoberta de novos fármacos de interesse médico e farmacêutico: fragilidades e pespectivas. Revista Brasileira de Farmacognosia, v.16, supl., p.678-89, 2006.

ALBUQUERQUE, A.P. et al. Medicinal and magic plants from a public market in Northeastern Brazil. Journal of Ethnopharmacology, v.110, n.1, p.76-91, 2007.

ALMEIDA, C.F.C.B.R.; ALBUQUERQUE, U.P. Uso e conservação de plantas e animais medicinais no estado de Pernambuco (Nordeste do Brasil): um estudo de caso. Interciencia, v.27, n.6, p.276-85, 2002.

ANNICHINO, G.P. et al. Medicina caseira em sete localidades da região de Bauru, São Paulo. Caderno de Saúde Pública Rio de Janeiro, v.2, n.2, p.150-66, 1986. ARAÚJO, E.C. et al. Uso de plantas medicinais pelos pacientes com câncer de hospitais da rede pública de saúde em João Pessoa (PB). Revista Espaço para a Saúde, v.8, n.2, p.44-52, 2007.

ARNOUS, A.H. et al. Plantas medicinais de uso caseiro - 
conhecimento popular e interesse por cultivo comunitário. Revista espaço para a Saúde, v.6, n.2, p.1-6, 2005.

AURICCHIO, M.T.; BACCHI, E.M. Folhas de Eugenia uniflora L. (pitanga): propriedades farmacobotânicas, químicas e farmacológicas. Revista do Instituto Adolfo Lutz, v.62, n.1, p.55-61, 2003.

BEZERRA, A.M.E. et al. Produção e composição química da macela em função da época de colheita. Horticultura Brasileira, v.26, n.1, p.26-9, 2008.

BOFF, L. Saber cuidar, ética do humano: compaixão pela terra. Petrópolis: Vozes, 2008. 199p.

BRAGA, R. Plantas do Nordeste, especialmente do Ceará. 2.ed. Fortaleza: Imprensa Oficial, 1960. 540p. BRASILEIRO, M.T. et al. Ximenia americana L.: botânica, química e farmacologia no interesse da tecnologia farmacêutica. Revista Brasileira de Farmácia, v.89, n.2, p.168-71, 2008.

CASTELLUCCI, S. et. al. Plantas medicinais relatadas pela comunidade residente na Estação Ecológica de Jataí, município de Luís Antonio, São Paulo: uma abordagem etnobotânica. Revista Brasileira de Plantas Medicinais, v.3, n.1, p.51-60, 2000.

COSTA-NETO, E.M.; OLIVEIRA, M.V.M. The use of medicinal plants in the country of Tanquinho, state of Bahia, North-eastern Brazil. Revista Brasileira de Plantas Medicinais, v.2, n.2, p.1-8, 2000.

CRONQUIST, A. An integrated system of classification of flowering plants. New York: Columbia University Press, 1981. 1262p.

FRANCO, E.A.P.; BARROS, R.F.M. Uso e diversidade de plantas medicinais no Quilombo Olho D'água dos Pires, Esperantina, Piauí. Revista Brasileira de Plantas Medicinais, v.8, n.3, p.78-88, 2006.

IBAMA. Instituto Brasileiro do Meio Ambiente e dos Recursos Naturais Renováveis. Plano de gestão e diagnóstico geoambiental e sócio-econômico da APA da Serra da Ibiapaba. Fortaleza: IEPS/UECE, 1998. 99p. IPNI. The International Plant Names Index. Disponível em: <http://www.ipni.org>. Acesso em: 16 ago. 2009.

IBGE. Instituto Brasileiro de Geografia e Estatística. Contagem da População 2007. Rio de Janeiro: IBGE, 2007. Disponível em: <http://www.ibge.gov.br>. Acesso em: 17 out. 2008.

IBGE. Instituto Brasileiro de Geografia e Estatística. Resolução N. R. PR. № 05 de 10 de outubro. Diário Oficial da União, Brasília, DF, 11 de outubro de 2002, Seção 1, p.48-69.

JUDD, W.S. et al. Plant systematics: a phylogenetic approach. Sunderland: Sinauer associates, 1999. 462p. MAIOLI-AZEVEDO, V.; FONSECA-KRUEL, V.S. Plantas medicinais e ritualísticas vendidas em feiras livres no município do Rio de Janeiro, RJ, Brasil: estudo de caso nas zonas Norte e Sul. Acta Botanica Brasilica, v.21, n.2, p.263-75, 2007.

MARTIN, G. J. Ethnobotany: a methods manual. "People and Plants" conservation manuals. London: Chapman Hall, 1995. 263p.

MATOS, F.J.A. Plantas medicinais: guia de seleção e emprego de plantas usadas em fitoterapia no Nordeste do Brasil. v.2, Fortaleza: IOCE, 1989. 144p.

MEDEIROS, R.M. Estudo agrometeorológico para o estado do Piauí. Teresina: SEMA, 2004. 119p.

MS. Ministério da Saúde. Dispõe sobre Portaria 971, DE 3 DE MAIO DE 2006. Aprova a Política Nacional Práticas Integrativas e Complementares (PNPIC) no Sistema Único de Saúde. Diário Oficial da União, n.84, 2006.

MONTELES, R.; PINHEIRO, C.U.B. Plantas medicinais em um quilombo maranhense: uma perspectiva etnobotânica. Revista de Biologia e Ciências da Terra, v.7, n.2, p.38-48, 2007.

MORAIS, S.M. et al. Plantas medicinais usadas pelos índios Tapebas do Ceará. Revista Brasileira de Farmacognosia, v.15, n.2, p.169-77, 2005.

MORI, S.A. et al. Manual de manejo do herbário fanerogâmico. 24.ed. Bahia: Centro de Pesquisa do Cacau, 1989. 104p.

OLIVEIRA, C.J.; ARAÚJO, T.L. Plantas medicinais: uso e crenças de idosos portadores de hipertensão arterial. Revista Eletrônica de Enfermagem, v.9, n.1, p.93-105, 2007.

OMS. Organização Mundial da Saúde. Classificação estatística internacional de doenças e problemas relacionados à saúde. 10.ed. São Paulo: Editora da Universidade de São Paulo, 2000. 354p.

SILVA, A.G. Plantas na terapêutica moderna: tendências, riscos e estratégias de conservação. Natureza on line, v.2, n.2, p.34-6, 2004. Disponível em: <http:// www.naturezaonline.com.br>. Acesso em: 17 out. 2008. SILVA, J.G. et al. Atividade antimicrobiana do extrato de Anacardium occidentale L. em amostras multiresistentes de Staphylococcus aureus. Revista Brasileira de Farmacognosia, v.17, n.4, p.572-7, 2007.

SILVA, V.A. Etnobotânica dos índios Fulni-ô (Pernambuco, Nordeste do Brasil). 2003. 132p. Tese (DoutoradoBotânica) - Universidade Federal de Pernambuco, Recife. SOUZA, L.F. Recursos vegetais usados na medicina tradicional do Cerrado (comunidade de Baús, Acorizal, MT, Brasil) Revista Brasileira de Plantas Medicinais, v.9, n.4, p.44-54, 2007.

TORRES, A.R. et al. Estudo sobre o uso de plantas medicinais em crianças hospitalizadas da cidade de João Pessoa: riscos e benefícios. Revista Brasileira de Farmacognosia, v.15, n.4, p.373-80, 2005.

TROTTER, R.T.; LOGAN, M.H. Informant consensus: a new approach for identifying potentially effective medicinal plants. In: ETKI, N.L. (Ed.) Plants in indigenous medicine and diet. New York: Redgrave, 1986. p.91-112.

Rev. Bras. PI. Med., Botucatu, v.14, n.3, p.476-486, 2012. 